\title{
Do Modelo Matemático à Modelagem Matemática: descontinuidades históricas ${ }^{1}$
}

\author{
From Mathematical Model to Mathematical Modeling: \\ historical discontinuities
}

Maria Carolina Machado Magnus*
(D) ORCID iD 0000-0002-2834-9293
Ademir Donizeti Caldeira**
(D) ORCID iD 0000-0003-0290-9851
Claudia Glavam Duarte ${ }^{* * *}$
(D) ORCID iD 0000-0002-8608-5855

Resumo

O presente artigo tem por objetivo problematizar o discurso da Modelagem Matemática na Educação Matemática, evidenciando uma de suas descontinuidades históricas - do modelo à modelagem. Os aportes teóricometodológicos vinculam-se às teorizações do filósofo Michel Foucault. O material analítico abrange teses e dissertações sobre Modelagem Matemática na Educação Matemática, defendidas no Brasil no período de 1976 a 1999. A análise desses materiais evidenciou que o discurso da Modelagem, ao se entrelaçar ao discurso construtivista, na década de 1980, desloca o sentido de estudar matemática a partir de modelos enquanto produto para a construção de modelos enquanto processo.

Palavras-chave: Modelo Matemático. Modelagem Matemática. Descontinuidades. Construtivismo.

\begin{abstract}
The present article aims to problematize the discourse of Mathematical Modeling in Mathematics Education, highlighting one of its historical discontinuities - from model to modeling. The theoretical-methodological contributions are linked to the philosopher Michel Foucault theorizations. The analytical material includes these theorizations and dissertations on Mathematical Modeling in Mathematics Education, advocated in Brazil from 1976 to 1999. The analysis of these materials showed that the Modeling discourse, when intertwining with the constructivist discourse, in the 1980s, displaces the sense of studying mathematics from models as a product for the construction of models as a process.
\end{abstract}

Keywords: Mathematical Model. Mathematical Modeling. Discontinuities. Constructivism.

\footnotetext{
${ }^{1}$ Este artigo faz parte da pesquisa de doutorado da primeira autora, sob orientação do segundo e terceiro autores. * Doutora em Educação pela Universidade Federal de São Carlos (UFSCAR). Mestra em Educação Científica e Tecnológica pela Universidade Federal de Santa Catarina (UFSC). Professora do Departamento de Educação do Campo da Universidade Federal de Santa Catarina. Endereço para correspondência: Rua: Servidão das Jaboticabeiras, 111, Florianópolis/SC, Brasil, CEP: 88037-542. E-mail: maria.carolina87@ hotmail.com.

** Doutor em Educação pela Universidade Estadual de Campinas (UNICAMP). Professor do Departamento de Metodologia de Ensino da Universidade Federal de São Carlos (UFSCAR). Endereço para correspondência: Rua Roberval Pozzi, 50, Santa Marta, São Carlos/SP, Brasil, CEP: 13.564-230. E-mail: mirocaldeira@ gmail.com.

*** Doutora em Educação pela Universidade do Vale do Rio dos Sinos (Unisinos). Coordenadora do curso de Licenciatura em Educação do Campo da Universidade Federal do Rio Grande do Sul (UFRGS), campus litoral. Endereço para correspondência: Travessa Sapiranga, 1257, Tramandaí/RS, Brasil, CEP 95590-000. E-mail: claudiaglavam@hotmail.com.
} 


\section{Descontinuidades históricas: uma conceituação a partir de Foucault}

É preciso pegar as coisas para extrair delas as visibilidades. E a visibilidade de uma época é o regime de luz, e as cintilações, os reflexos, os clarões que se produzem no contato da luz com as coisas (DELEUZE, 2000, p. 120).

Ao olharmos, analiticamente, para o discurso da Modelagem Matemática, buscamos lançar luzes para extrair visibilidades que, aparentemente, estariam apagadas pela falta de clarões. Dito de outro modo, trata-se de fazer aparecer, por mais contraditório que possa parecer, o invisível que não está escondido, uma vez que, ainda que os discursos estejam presentes, alguns carecem de mais luzes para serem vistos. As visibilidades que buscamos extrair e analisar estão relacionadas com as descontinuidades históricas desse discurso.

A noção de descontinuidade é um elemento central nas discussões empreendidas por Foucault. No entanto, antes de adentrarmos no conceito, julgamos importante fazer um breve histórico, situando o filósofo a partir de diálogos que ele engendrou com outros pensadores historiadores da ciência e historiadores que compuseram a revista dos Annales $^{2}$.

Segundo Le Goff (2003, p. 205-206), o que interessava a Foucault, nos Annales, eram as descontinuidades identificáveis na obra $O$ Mediterrâneo, do historiador Fernand Braudel. “A noção de 'longa duração' o interessava - ele disse - mas essencialmente porque ela permitia, justamente, perceber melhor as descontinuidades, as rupturas, o folhear das diversas durações temporais".

Referente à longa duração, Foucault faz uma crítica sobre a existência de três temporalidades (curta, média e longa) definidas por Braudel. Para Foucault, a temporalidade é mais complexa e múltipla, não se limita a apenas três períodos. "A história não é, portanto, uma duração; é uma multiplicidade de tempos que se emaranham e se envolvem uns aos outros. É preciso, portanto, substituir a velha noção de tempo pela noção de duração múltipla" (FOUCAULT, 2013b, p. 308, grifos nossos).

Essa noção de descontinuidade, tão importante a Foucault, está relacionada aos historiadores, e, consequentemente, está ligada à história serial, campo principal dos Annales na era Braudel (PEREIRA, 2013). As ressonâncias entre a história serial e Michel Foucault podem ser evidenciadas, segundo Pereira (2013), ao longo dos anos 1960, principalmente, na introdução do livro A arqueologia do saber, em alguns trechos de A Ordem do discurso e no

\footnotetext{
${ }^{2}$ A revista, pouco a pouco, foi convertendo-se em uma escola. Burke (1991) sugere que, talvez, seja preferível, falar em um movimento dos Annales, não numa escola, já que o estereótipo de escola ignora tanto as divergências individuais entre seus membros quanto seu desenvolvimento no tempo. Seguindo a sugestão de Burke, ao nos referirmos aos Annales, utilizamos revista ou movimento.
} 
texto Retornar à História, publicado na coleção Ditos e Escritos - volume II (FOUCAULT, 2014, 2014b, 2013b).

Foucault foi bem-sucedido nesse diálogo com os historiadores e, para Ladurie, "a introdução à A Arqueologia do Saber é a primeira definição da história serial” (LADURIE apud PEREIRA, 2013, p. 72).

Para Machado (2007), a arqueologia sempre procurou se situar em relação à epistemologia - história epistemológica. Porém, a arqueologia não se estabelece pelos mesmos princípios que a história epistemológica; ela assume, em suas análises, uma posição bastante diferente: enquanto a epistemologia pretende estar à altura das ciências, a arqueologia reivindica sua independência em relação a qualquer ciência.

Enquanto a história epistemológica investiga a produção de verdades na ciência, a história arqueológica não privilegia a questão normativa da verdade, nem estabelece uma ordem temporal de recorrências a partir da racionalidade científica atual. Isso significa dizer que a arqueologia realiza uma história dos saberes de onde desaparece qualquer traço de uma história do progresso da razão, seja ele contínuo ou descontínuo.

Parece-nos mesmo que a riqueza do método arqueológico é ser um instrumento capaz
de refletir sobre as ciências do homem como saberes, neutralizando a questão de sua
cientificidade e escapando do desafio impossível de realizar, nesses casos, uma
recorrência histórica, como deveria fazer a análise epistemológica. O que não
significa, como veremos, abandonar a exigência de uma análise conceitual capaz de
estabelecer descontinuidades, certamente não epistemológicas, mas arqueológicas,
isto é, situadas no nível dos saberes (MACHADO, 2007, p. 9).

A noção de descontinuidade, que tanto interessava a Foucault, e que é essencial em sua arqueogenealogia, também dialoga com certos historiadores das ciências, tais como Bachelard (1972). Vejamos o porquê.

Bachelard (1972) rompe com a epistemologia continuísta, para a qual a ciência se desenvolvia de forma cumulativa e linear. Para o autor, a ciência desenvolve-se em um progresso descontínuo. Nesse sentido, Bachelard se coloca como um crítico da concepção positivista-comteana de ciência, uma vez que, para essa perspectiva, a ciência se daria através de um progresso contínuo, linear e cumulativo. Ou seja, para o positivismo, as novas teorias seriam consequência das teorias anteriores, seriam, portanto, um acúmulo, uma continuidade das mesmas ideias.

Ao traçar sua crítica à ciência moderna, Bachelard (1972, p. 30, grifos do autor) escreve que "uma das objeções mais naturais dos continuistas da cultura vem ser evocar a continuidade histórica. Visto que se faz um relato contínuo dos acontecimentos, acredita-se facilmente reviver os acontecimentos na continuidade do tempo". Dessa forma, Bachelard rompe com a 
ideia de continuidade, já que, para ele, a história epistemológica apresentou mais descontinuidades e rupturas do que continuidade. Para Bachelard, de acordo com Machado, há uma descontinuidade entre conhecimento científico e conhecimento comum, para o qual "o objeto científico não é natural, é construído" (MACHADO, 2007, p. 30) e descontinuidade entre a ciência e a pré-ciência, ou seja, "o saber que ocupava abusivamente seu lugar" (MACHADO, 2007, p. 31).

Cabe assinalar que a ideia de progresso científico não desaparece das discussões engendradas por Bachelard. Porém, há uma diferença entre o progresso acreditado pelos continuístas e pelos descontinuístas. Enquanto para a história positivista o progresso se desenvolvia de forma linear e contínua, para Bachelard o progresso se desenvolve a partir de descontinuidades, por meio de rupturas, de negação do passado. O progresso é um componente essencial da ciência, é a própria dinâmica da cultura científica. Já na análise arqueológica e genealógica, desaparece qualquer traço de progresso, seja ele contínuo ou descontínuo.

Apresentada a noção de descontinuidade dos autores citados, retomemos a arqueologia de Foucault. Em seu livro A Arqueologia do Saber (2014, p. 25), o autor inicia a obra fazendo uma crítica às análises históricas que buscam a continuidade e a linearidade dos fenômenos. Ele argumenta que é preciso "libertar-se de todo um jogo de noções que diversificam, cada uma à sua maneira, o tema da continuidade".

Foucault (2014, p. 6) afirma que o grande problema que se coloca "a tais análises históricas não é mais saber por que caminhos as continuidades se puderam estabelecer; de que maneira um único e mesmo projeto pôde-se manter e constituir, para tantos espíritos diferentes e sucessivos, um horizonte único" e que "a descontinuidade era o estigma da dispersão temporal que o historiador se encarregava de suprimir da história" (FOUCAULT, 2014, p. 10). Dessa maneira, o que o filósofo propõe com seu método arqueológico é contestar o uso da continuidade nas análises históricas.

Assim, na introdução à A Arqueologia do Saber, Foucault menciona a discussão engendrada por Bachelard.

Atos e liminares epistemológicos descritos por G. Bachelard: suspendem o acúmulo
indefinido dos conhecimentos, quebram sua lenta maturação e os introduzem em um
tempo novo, os afastam de sua origem empírica e de suas motivações iniciais, e os
purificam de suas cumplicidades imaginárias; prescrevem, desta forma, para a análise
histórica, não mais a pesquisa dos começos silenciosos, não mais a regressão sem fim
em direção aos primeiros precursores, mas a identificação de um novo tipo de
racionalidade e de seus efeitos múltiplos (FOUCAULT, 2014, p. 4-5, grifos do autor).

A arqueologia foucaultiana também suspende o acúmulo indefinido dos conhecimentos, a busca pelas origens e pelos primeiros precursores, a partir da descontinuidade. Porém, as 
descontinuidades arqueológicas e genealógicas possuem diferenças das descontinuidades epistemológicas. Na obra intitulada As ciências da vida: de Canguilhem a Foucault, a filósofa Portocarrero (2009) apresenta tal distinção ao afirmar que

\begin{abstract}
No nível da análise epistemológica, as descontinuidades históricas são diacrônicas. Marcam incompatibilidade e mutações, em épocas diferentes, através da recorrência estabelecida a partir do critério da atualidade. No nível arqueológico e da genealogia do poder, trata-se de descontinuidades diacrônicas, que traçam o miar de épocas diferentes, mas articuladas a continuidades sincrônicas que marcam compatibilidades e coerências numa mesma época, através não do critério da recorrência e da atualidade, mas da positividade e da contemporaneidade dos saberes e dos poderes (PORTOCARRERO, 2009, p. 26-27, grifos nossos).
\end{abstract}

São essas descontinuidades diacrônicas e sincrônicas que pretendemos reintroduzir na história do discurso da Modelagem Matemática. Para tanto, o presente artigo tem por objetivo problematizar o discurso da Modelagem Matemática na Educação Matemática, evidenciando uma de suas descontinuidades históricas - do modelo à modelagem. Para tanto, buscamos analisar os buracos, os percalços, as rupturas, as rachaduras, os meandros (...) que constituem esse discurso.

\title{
2 Das Ferramentas Teóricas e Metodológicas
}

Para a escrita deste trabalho, o material analítico selecionado foi constituído por teses e dissertações com foco em Modelagem Matemática, defendidas no Brasil, no período de 1976 a 1999. Tal escolha justifica-se pelo fato de que é nesse ínterim que ocorre o deslocamento de Modelos à Modelagem, de acordo com Fiorentini (1996), Silveira (2007), Magnus (2018), entre outros.

Para compormos nosso olhar, buscamos ferramentas metodológicas na oficina de Michel Foucault. A princípio, se compreendermos método no sentido atribuído pelo pensamento moderno, podemos dizer que não há um método foucaultiano. Porém, se compreendermos método como "uma certa forma de interrogação e um conjunto de estratégias analíticas de descrição" (VEIGA-NETO, 2007, p. 17), podemos dizer que ele existe.

Os elementos que compõem nosso conjunto de estratégias referem-se a alguns cuidados metodológicos que tivemos ao realizar a análise. Ao escrutinarmos o material analítico tivemos o cuidado de "analisar o dictum como um monumento e não como um documento. Isso significa que a leitura (ou escuta) do enunciado é feita pela exterioridade do texto, sem entrar propriamente na lógica interna que comanda a ordem dos enunciados" (VEIGA-NETO, 2007, p. 104, grifos do autor). Ou seja, olhamos para as descontinuidades em sua exterioridade, por meio daquilo que as cerca e as sustenta. 
Ainda, a análise monumental não está atrás de uma suposta verdade, "nem mesmo busca uma essência original, remota, fundadora, tentando encontrar, nos não-ditos dos discursos sob análise, um já-dito ancestral e oculto" (VEIGA-NETO, 2007, p. 98). Ao analisarmos as descontinuidades não buscamos um não dito, pois, “o que nos interessa descobrir já está lá; basta saber ler" (VEIGA-NETO, 2007, p. 105).

A análise foi realizada sob um já dito. Isto é, analisamos o dito, o que está escrito nas teses e nas dissertações e não a intenção que tiveram de dizer ou aquilo que poderia ser dito, que estaria oculto em sua escrita. Analisamos o que foi dito e as condições que possibilitaram aquilo ser dito e não outra coisa em seu lugar. Ou seja, não buscamos o não dito, pois, "até mesmo os silêncios são apenas silêncios, para os quais não interessa procurar preenchimentos; eles devem ser lidos pelo que são e não como não ditos que esconderiam um sentido que não chegou à tona do discurso" (VEIGA-NETO, 2007, p. 98).

Nessa perspectiva, o olhar que lançamos sobre o material empírico não buscou “descobrir verdades ocultas, mas tornar visível exatamente o que já está visível” (ARTIÈRES, 2004, p. 15). É um visível que se torna opaco por sua proximidade. Dar visibilidade ao visível é lançar luzes a essa opacidade e mostrar aquilo que de tão próximo, tão ligado, indescritivelmente perto, não conseguimos perceber. Assim, buscamos fazer ver o que já vemos, mas que não percebemos que o vemos, justamente por estar "muito na superfície das coisas" (FOUCAULT, 2013a, p. 152).

Ainda, nosso olhar minucioso também não buscou uma origem, não foi em busca da primeira vez em que a Modelagem foi dita. Isso porque, segundo Foucault (2011, p. 17), a busca por uma origem é "[...] se esforçar para recolher nela a essência exata da coisa, sua mais pura possibilidade, sua identidade cuidadosamente recolhida em si mesma”. E o olhar que lançamos sobre o material analítico não buscou uma essência para a Modelagem, nem o que é esse discurso, nem qual sua origem.

\section{Descontinuidades... Regularidades... Uma Análise em Movimento}

Ao lançarmos luzes sobre o material analítico, evidenciamos que, para alguns autores e pesquisadores, o discurso da modelagem existiu desde sempre, desde o início do desenvolvimento da Matemática, como podemos ler no excerto de Floriani (1997, p. 36, grifos nossos): "A modelagem está presente na vida do homem, desde as épocas mais remotas. A criação de modelos para explicar, conhecer a realidade, é própria do ser humano e seu emprego perpassa diferentes áreas" (FLORIANI, 1997, p. 36, grifos nossos). 
E ainda: “A Modelagem Matemática tem sido feita desde a Pré-História. O homem vive na busca para conhecer e compreender o seu ambiente. Para conhecê-lo, o homem procura compreendê-lo, explorando-o, valendo-se, em parte, da sua racionalidade" (BURAK, 1992, p. 61, grifos nossos).

Na perspectiva de Gazzetta (1989, p. 16, grifos nossos):

Modelos matemáticos podem ser encontrados no início do desenvolvimento da Matemática. Certamente conceitos tais como número, linha, plano, conjunto, função, probabilidade, etc., são modelos de alguma realidade e também o são o Teorema de Pitágoras, semelhança de triângulos, séries geométricas, as leis de movimento de Newton e muitos outros conceitos e teoremas matemáticos.

$[\ldots]$

Embora os modelos matemáticos tenham sido usados desde que a Matemática começou a existir, somente no último século foi introduzido o termo "modelo" na matemática, quando as geometrias não euclidianas de Lobachewski e Riemann ganharam aceitabilidade na Matemática.

Esses excertos apontam a existência de modelos desde o início do desenvolvimento da matemática, desde que a Matemática começou a existir ${ }^{3}$. Para esses pesquisadores, a modelagem está presente na vida do homem, desde as épocas mais remotas, desde a préhistória, e criar modelos é próprio do ser humano. Resumindo, a Modelagem existe desde sempre. No entanto, o que é que se entende por desde sempre? A origem dos modelos coincide com a origem do homem? Será que estamos falando dos mesmos modelos? Da mesma Modelagem? Das mesmas atividades? Quais descontinuidades são evidenciadas nessa história?

Ao olharmos para os trabalhos defendidos na década de 1970 e 1980, percebemos que havia, pelo menos, três tipos de modelos matemáticos que caracterizariam o ensino: concretos, gráficos e abstratos.

\footnotetext{
${ }^{3}$ Tais trechos retomam as passagens expostas, anteriormente, de trechos do texto de Gazzetta (1989). Em sua obra, a autora não explicita o que compreende pelo início do desenvolvimento da matemática, mas, acreditamos que esteja falando da matemática enquanto um campo de saber institucionalizado.
} 
"Os modelos concretos são caracterizados pelo uso de objetos concretos para substituir algum outro objeto (o original) numa investigação" (GAZZETTA, 1989, p. 23, grifos nossos).

O modelo [concreto] é um artifício elaborado pelo professor para sugerir mais com menos esforço certas ideias. Daí, não basta substituir retas e planos por varetas e placas de papelão para que estejamos ensinando por modelo concreto. É preciso que isto esteja adequado à ideia a ser transmitida (WILMER, 1976, p. 35 , grifos nossos).

O modelo concreto é um caminho para a aprendizagem de certas situações matemáticas. Tal situação pode ser: uma definição a ser motivada, um teorema a ser intuído, um enfoque que estimule a generalização, uma teoria a ser antecipada, uma construção, ou qualquer outro tipo de questão (WILMER, 1976, p. 31, grifos nossos).

Entre os modelos gráficos considerados bastante precisos e reconhecidamente úteis estão: o plano cartesiano, os diagramas de Venn para conjuntos; os papygramas; a épura da geometria descritiva (WILMER, 1976, p.41, grifos nossos).

Uma característica do seu uso do ensino [modelos concretos] é que o aluno desconheça o assunto a ser ilustrado pelo exercício, de modo que sua concentração inicial seja o exercício prático em si. Só depois a solução será geometrizada e conceitualizada. A menção do assunto do exercício desvirtua e precipita o raciocínio do aluno (WILMER, 1976, p. 56, grifos nossos).

A figura é um desses recursos, e o modelo gráfico é um tipo especial de figura, já que, como o modelo concreto, não se limita a um simples reflexo de objetos teóricos em outro nível. Implica numa figura especialmente criada para certo tipo de informação a ser transmitida (WILMER, 1976, p. 39, grifos nossos).

O modelo gráfico desempenha no ensino da matemática o mesmo papel que os materiais didáticos. São auxiliares no processo de ensino-aprendizagem, possibilitando uma abordagem mais intuitiva de um determinado conceito matemático (MÜLLER, 1986, p. 62, grifos nossos).

Entendo por modelo gráfico de um conceito (algébrico, analítico, geométrico etc.) uma figura geométrica ou um diagrama, suficientemente bem definidos, de modo que o raciocínio sobre eles tenha quase a mesma validade que o raciocínio formal sobre o conceito (WILMER, 1976, p. 38, grifos nossos).

Modelos matemáticos abstratos são aqueles que descrevem objetos por meio de elementos gráficos ou símbolos matemáticos de natureza definida, cuja manipulação tem um grande potencial para a introdução de novos conhecimentos (GAZZETTA, 1989, p. 24, grifos nossos).

Os modelos concretos são caracterizados pelo uso de objetos concretos; já os modelos gráficos podem ser, por exemplo, o plano cartesiano; os modelos abstratos são aqueles que descrevem objetos por meio de elementos gráficos ou símbolos matemáticos de natureza definida. No que se refere ao uso em sala de aula, o professor poderia iniciar seu trabalho a partir dos modelos concretos, passar pelos modelos gráficos, até atingir o nível abstrato 
(SÁNCHEZ, 1979), partindo do mais fácil (concreto) para o mais difícil (abstrato) - baseado nas ideias piagetianas.

A partir da década de 1990, esses modelos (concretos, gráficos e abstratos), tal e qual foram discutidos por Wilmer (1976), Sanchez (1979), Müller (1986) e Gazzetta (1989), perdem força no discurso da Modelagem. Os trabalhos defendidos, posteriormente, fazem referência à palavra modelo, não o distinguindo mais em: concreto, gráfico e abstrato.

No que se refere a esses primeiros trabalhos, como mostrado a seguir, os pesquisadores apontam que os modelos no ensino de Matemática possibilitariam uma nova forma de trabalhar com os conteúdos matemáticos, contribuindo para seu ensino e aprendizagem, a partir de situações do dia a dia.

Não podemos esquecer que a matemática teve origem no cotidiano das pessoas, medindo terras, construindo casas e realizando transações comerciais. Mas infelizmente, nestes dois mil anos, em paralelo com o formalismo não foi desenvolvida uma pedagogia mais dinâmica, de modo que a matemática tradicional da escola só em condições especiais é chamada a participar do dia-a-dia do homem comum (WILMER, 1976, p. 31, grifos nossos).

Os modelos, também, problematizariam as características da Matemática, do formalismo e da abstração, que circulavam/circulam como verdadeiras no campo educacional, como podemos ver no excerto abaixo:

Com isso, se no decorrer de nossa prática docente enfatizarmos o desenvolvimento do conteúdo e de exercício privilegiando aspectos formais desta disciplina, estaremos destacando uma de suas características. Enquanto que, ao enfatizarmos suas aplicações, estaremos proporcionando condições para que um outro aspecto da matemática seja trabalhado pelo aluno, fazendo com que um conceito mais amplo sobre o papel da matemática para o desenvolvimento social e científico seja elaborado por ele (MÜLLER, 1986, p. i, grifos nossos).

Para Müller (1986), o ensino de Matemática, quando privilegia as aplicações de conteúdos, possibilita que os alunos percebam outra característica da Matemática: seu papel no desenvolvimento social e científico. Essa forma de ensinar a disciplina se diferenciaria do ensino tradicional, que só em condições especiais proporciona discussões que se aproximem de situações do dia a dia dos alunos.

Sendo assim, ao trabalhar com modelos, seria possível problematizar uma das verdades bastante disseminada pelo discurso da Matemática: seu grau de neutralidade, da Matemática como ciência neutra, vinculada exclusivamente a processos de objetivação, como se processos de subjetivação não a atravessassem (DUARTE, 2011, p. 73). Essa neutralidade desvincula a Matemática do mundo real, devido a suas características formais e abstratas, e acaba tornando possíveis enunciados como os alunos têm dificuldade na aprendizagem da Matemática ou a 
Matemática é distante da realidade. Em efeito, os modelos matemáticos possibilitariam minimizar o grau de neutralidade da Matemática, dando visibilidade a uma outra característica dela: seu papel para o desenvolvimento social e científico, a partir de suas aplicações.

Além de discutir, em sua pesquisa, sobre as características da Matemática e apresentar os modelos matemáticos como uma forma de dar visibilidade a outra característica dessa disciplina, Müller (1986) (re)configura a expressão modelos matemáticos, colocando na ordem do discurso a expressão Modelagem Matemática.

Foi somente a partir da segunda metade da década de 80 que surgiram as primeiras dissertações de mestrado que passaram a explorar ou utilizar a denominação "modelagem matemática”. O primeiro estudo desse período - Müller (1986) - foi produzido na FE-UNICAMP e este pode ser considerado como um trabalho que contempla a transição dos "modelos matemáticos" para a "modelagem matemática" no ensino da matemática (FIORENTINI, 1996, p. 5, grifos nossos).

Fiorentini (1996), ao discutir sobre a modelagem, argumenta que o trabalho de Müller (1986) faz uma transição de Modelos para Modelagem. Porém, o que Müller faz não é uma transição de expressões; a autora nomeia como Modelagem o processo de obtenção de um modelo. Ou seja, para se obter um modelo matemático é utilizado um processo de construção que é chamado de Modelagem.

Um modelo matemático é o sistema obtido após o terceiro estágio do processo de modelagem, ou seja, é a explicitação das relações matemáticas entre os dados iniciais do problema em questão (MÜLLER, 1986, p. 29, grifos nossos).

É importante observarmos que um modelo real constitui-se na primeira tentativa de descrever o fato observado, além disso, esta etapa possui um caráter fundamental para o processo de modelagem, pois é através do modelo real que selecionamos as variáveis e as relações que determinarão o modelo matemático (MÜLLER, 1986, p. 67, grifos nossos).

Após estas considerações cremos que fica claro que a estratégia de ensino não utiliza apenas o modelo matemático mas sim, todo o processo de modelagem e, além disso, toda uma ideia de ensinar matemática colocando-a dentro de um contexto comum aos alunos, relacionando-a com as ciências e o dia a dia das pessoas (MÜLLER, 1986, p. 68, grifos nossos).

Outro passo na sequência da Modelagem é estabelecer a forma como essas variáveis devem estar relacionadas para melhor exprimir o problema a ser estudado, é a construção do modelo (BURAK, 1987, p. 37, grifos nossos).

$\mathrm{Na}$ literatura científica o termo "modelagem" é usualmente associado com o processo de construção de um modelo abstrato descritivo de algum sistema concreto. (GAZZETTA, 1989, p. 26, grifos nossos).

A representação do mundo real por meio de linguagem matemática denomina-se Modelo e a estratégia usada para se chegar ao modelo, Modelagem (BIEMBENGUT, 1990, p. 3, grifos da autora). 
Modelagem Matemática é o processo de análise dos procedimentos recorrentes envolvidos na formulação de um modelo matemático a partir de uma dada situação (BIEMBENGUT, 1990, p. 10, grifos nossos).

A construção do modelo é uma fase muito importante do processo, pois pode envolver criatividade, habilidade, aplicação ou construção de novos conceitos matemáticos e análise das variáveis envolvidas. É uma fase muito rica, propiciada pelo Método da Modelagem. Algumas vezes, um grande tempo pode ser investido na construção do modelo (BURAK, 1992, p. 185, grifos nossos).

Modelagem é o processo da representação da realidade num modelo (ALMEIDA, 1993, p. 19, grifos nossos).

A Modelagem é usualmente associada com o processo de construção de um modelo de algum sistema concreto (SCHEFFER, 1995, p.66, grifos nossos).

A modelagem é um processo que leva a um Modelo permitindo avaliar, fazer previsões, enfim, dar respostas a determinadas perguntas e por isso, podemos utilizar a modelagem em todas as áreas e disciplinas (FLORIANI, 1997, p. 37, grifos nossos).

De modo muito simplificado, caracterizo aqui como modelo a descrição matemática dos problemas ambientais que foram escolhidos pelos alunos, e de modelagem matemática, todo o processo de desenvolvimento para se chegar a um produto final (CALDEIRA, 1998, p. 130, grifos nossos).

Modelagem Matemática é o processo envolvido na obtenção de um modelo (BIEMBENGUT, 1997, p. 66, grifos nossos).

É só a partir da década de 1980 que a expressão Modelagem Matemática é utilizada para se referir ao processo de construção de um modelo. A entrada em cena dessa expressão, no discurso da Modelagem, pode estar entrelaçada a um outro discurso que passou a circular no meio educacional, o construtivismo. Esse discurso coloca em ordem uma outra forma de ensino e aprendizagem: para essa nova abordagem, o conhecimento não é transmitido pelo professor através de uma aula expositiva (MATTHEWS, 2000). Para o construtivismo, o conhecimento é construído pelo aluno (AGUIAR J., 1998) a partir da mediação do professor. Através desse discurso, prioriza-se mais o processo do que o produto do conhecimento (FIORENTINI, 1995).

A partir da década de 1980, o discurso construtivista se expandiu pelo Brasil (REVAH, 2008) de tal maneira que muitos professores se referem a ele como a febre construtivista (VASCONCELOS, 1996). Esse discurso é apresentado como um prolongamento das ideias de Piaget do início do século XX (REVAH, 2008), o qual percebeu, através de observações de crianças, desde o nascimento até a adolescência, que o conhecimento se constrói na interação do sujeito com o meio em que vive (NIEMANN; BRANDOLI, 2012). 
Os estudos de Piaget apresentavam uma preocupação epistemológica, e não educacional, sendo que "um dos principais focos de interesse do autor suíço foi investigar o quanto a biologia poderia contribuir para o entendimento do modo como o homem adquire conhecimento" (SKALINSKI Jr., 2010, p. 2). No entanto, conforme irá defender Fossile (2010, p. 106), "pelo fato de seus estudos terem contribuído de maneira positiva para o entendimento de várias questões relacionadas à educação, ele acabou sendo incluído na teoria pedagógica educacional".

O construtivismo, no meio educacional, ganhou visibilidade e entrelaçou-se a diferentes discursos: Educação Matemática, Ensino de Ciências, Ensino de Língua Portuguesa, entre outros. No que se refere ao ensino de Língua Portuguesa, Emília Ferreiro ${ }^{4}$, a partir das pesquisas desenvolvidas por Piaget, focou seus estudos na leitura e escrita, no processo de alfabetização. O discurso construtivista, nas pesquisas dessa autora, "mostram que a escrita não é a simples cópia de um modelo, mas sim um processo de construção por parte da criança" (SANCHIS; MAHFOUD, 2010, p. 22). Já em relação ao ensino de ciências, tomando como ponto de partida uma perspectiva construtivista, o processo de aprendizagem estaria preocupado com a construção do conhecimento pelo aluno, e não com apresentação de produtos prontos da ciência. Segundo tal perspectiva, nas aulas de ciências, "as pré-concepções dos alunos sobre os fenômenos e sua atuação nas aulas práticas são férteis fontes de investigação para os pesquisadores como elucidação do que pensam e como é possível fazê-los progredir no raciocínio e análise dos fenômenos" (KRASILCHIK, 2000, p. 88).

Em Educação Matemática, também, a aprendizagem passa a ser vista não como uma cópia de modelos, mas como um processo de construção que pode levar a modelos. O discurso da Modelagem, ao nomear o processo de obtenção de um modelo como tal, desloca o sentido de ensinar a partir de modelos para o processo de construção destes, tendo o aluno como sujeito ativo nessa construção. Esse deslocamento pode estar entrelaçado às ideias do construtivismo, já que ocorre em meio à febre construtivista.

No entanto, ainda que tenhamos trazido alguns exemplos de como o construtivismo acabou incidindo no meio educacional, parece-nos que é possível pensar em diferentes construtivismos $^{5}$. Ainda assim, embora haja diferentes vertentes, há regularidades entre elas que possibilitam caracterizá-las enquanto pertencentes ao que se entende por construtivismo, e são esses pontos em comum que importam para esta discussão, como expomos a seguir.

\footnotetext{
${ }^{4}$ Emília Ferreiro é psicóloga e pedagoga argentina, radicada no México. Fez seu doutorado na Universidade de Genebra, sob orientação de Jean Piaget.

${ }^{5}$ Ver Matthews (2000) sobre essa discussão.
} 
Para Custódio et al (2013), numa tentativa de rompimento com os moldes tradicionais, criou-se, no cenário educativo, uma nova visão sobre o aluno e seu papel. Para as novas vertentes, o estudante "deixa de ser visto como um indivíduo passivo, vazio de conhecimento, e passa a assumir uma participação ativa no processo de aprendizagem" (CUSTÓDIO et al, 2013, p. 16, grifos nossos). Consequentemente, o papel do professor também foi redefinido: ele passa a ser o mediador e/ou facilitador do processo de aprendizagem do aluno (LEÃO, 1999).

Dentre os pressupostos da concepção construtivista, estão as afirmações de que $o$ aluno é um sujeito ativo na construção de seu conhecimento e, que mesmo antes de entrar na escola, possui alguns conhecimentos prévios sobre a língua escrita. Assim, ele precisa ter a possibilidade de refletir sobre as suas hipóteses, ou seja, durante o processo de ensino e de aprendizagem, os conhecimentos prévios das crianças, como um sujeito ativo, devem ser valorizados. Desse modo, as características do ensino tradicional, [...], são tomadas como totalmente opostas a um ensino construtivista. Percebe-se que essas características fazem parte dos semas negativos (rejeitados por esse discurso): o discurso construtivista traduz o seu Outro de acordo com aspectos negativos de seu próprio sistema (SILVA, 2011, p. 520-521, grifos nossos).

Esses pressupostos que são comuns a todas as vertentes construtivistas - aluno ativo, professor mediador, conhecimentos prévios, construção do conhecimento - possuem ressonância no discurso da Modelagem, como pode ser visto nas enunciações abaixo:

O educando é agente do processo, suas experiências e conhecimentos, adquiridos ou não formalmente, são essenciais para o decorrer do processo (MONTEIRO, 1991, p. 189, grifos nossos).

Outro aspecto que para nós é fundamental, é o levantamento e a formulação do problema ser feito pelo próprio aluno, garantindo, assim, uma aprendizagem significativa que apresenta um nível elevado de envolvimento, pois o aluno incluise como um todo na experiência a partir da qual aprende (GAZZETTA, 1989, p. 36, grifos nossos).

Face a tais perspectivas do conhecimento, a aprendizagem adquire conotações específicas. É vista como algo realizado pela pessoa que aprende e como sendo fruto dos seus interesses e das experiências que possuem correspondentes no seu campo fenomenológico. Trata-se, assim, de uma aprendizagem significativa para aquele que aprende. Não é, portanto, resultante do ensino exercido por uma terceira pessoa... (GAZZETTA, 1989, p. 91, grifos nossos).

O educador necessariamente tem que assumir um papel de facilitador, que parte da experiência do educando e não da sua, para a sistematização dos conteúdos envolvidos (MONTEIRO, 1991, p. 190, grifos nossos).

É uma pedagogia que exige do professor uma nova postura com relação ao ensino, começando com o questionamento da sua "genialidade", do ser depositário do "conhecimento" que seria a expressão da verdade objetiva, de ser aquele que "ensina" (BURAK, 1987, p. 30, grifos nossos).

Com essa prática educativa procura-se, através da ação do "fazer", chegar ao "saber" (BURAK, 1987, p. 13, grifos nossos). 
No estudo da matemática através da modelagem, as atividades se constituem na ação de refletir, de fazer, de construir, de concluir e de generalizar (BURAK, 1987, p. 32, grifos nossos).

Como pode-se perceber, a modelagem é um processo dinâmico, substituindo o ensino tradicional fundamentado sobre a transmissão e recepção de informações, por um processo que envolve noções e modelos em grande parte construídos ou elaborados pelos próprios alunos (GAZZETTA, 1989, p. 72, grifos nossos).

O discurso da Modelagem foi entrelaçado por outros discursos e, consequentemente, novos enunciados passam a circular e funcionar como verdadeiros. De acordo com as enunciações acima, as atividades de Modelagem seriam desenvolvidas através do fazer para chegar ao saber. Elas se constituiriam na ação de refletir, de fazer, de construir. Com foco no fazer e construir, o papel do aluno seria (re)definido, ele passaria a ser agente do processo, e seria incluído como um todo na experiência.

$\mathrm{Na}$ Modelagem, a aprendizagem passaria a ser vista como algo realizado pela pessoa que aprende. Além disso, as experiências e conhecimentos dos alunos, adquiridos ou não formalmente, são essenciais para o decorrer do processo. Se há um deslocamento do papel do aluno, o qual passa a ser ativo no desenvolvimento das atividades de Modelagem através da construção dos modelos, o professor também passaria a exercer um novo papel. A Modelagem exigiria do professor uma nova postura com relação ao ensino, do ser depositário do conhecimento para assumir um papel de facilitador. $\mathrm{O}$ discurso da Modelagem substituiria o ensino tradicional fundamentado sobre a transmissão e recepção de informações, por um processo que envolve noções e modelos em grande parte construídos pelos alunos.

Em efeito, o entrelaçamento entre o discurso da Modelagem e o discurso construtivista pode ter contribuído para o deslocamento da expressão Modelo Matemático enquanto produto para Modelagem Matemática enquanto processo.

\section{Algumas considerações finais}

O presente artigo teve por objetivo problematizar o discurso da Modelagem Matemática na Educação Matemática, evidenciando uma de suas descontinuidades históricas - do modelo à modelagem. A partir de uma perspectiva foucaultiana, lançamos clarões e buscamos os entrelaçamentos discursivos que possibilitaram outras discussões na Modelagem Matemática, a partir das descontinuidades diacrônicas e sincrônicas - que estariam apagadas. 
A análise do material evidenciou que os trabalhos, publicados na década de 1970, abordavam o termo Modelos Matemáticos no processo de ensino e aprendizagem de conteúdos matemáticos. Na década de 1980, emerge a expressão Modelagem Matemática, referindo-se ao processo de construção de um Modelo. A partir dessa descontinuidade, problematizamos as condições que possibilitaram a entrada em cena da expressão Modelagem Matemática.

Ao olharmos para a exterioridade do discurso, constatamos que a emergência dessa expressão poderia estar entrelaçada a outro discurso que passou a circular no meio educacional, na década de 1980: o construtivismo. A partir da análise engendrada, concluímos que o discurso da Modelagem, ao se entrelaçar com o discurso construtivista, desloca o sentido de ensinar a partir de modelos (produto) para construir modelos (processo). Esse deslocamento, de produto para processo, operou outras mudanças no discurso da Modelagem: aluna(o) passiva(o) para ativa(o), professor(a) transmissor(a) para mediador(a), desvalorização para valorização do conhecimento prévio da(o) aluna(o).

Nesse sentido, é possível inferir, a partir da análise aqui efetuada, que os deslocamentos, as rupturas e os novos engendramentos que emergem no campo discursivo estão imersos em relações de força e se produzem no enlace que fazem com discursos advindos de diversas áreas. Especificamente no caso aqui analisado, discursos do campo educacional de forma mais ampla. Analisar essas rupturas e reconfigurações significa, em última instância, visibilizar os processos de verdadeirização dos discursos e, dessa forma, apontar o caráter contingencial de sua produção e, quiçá, possibilitar outros modos de contarmos e fazermos a história.

\section{Referências}

AGUIAR JR., O. O papel do construtivismo na pesquisa em ensino de ciências. Revista Investigações em Ensino de Ciências, Porto Alegre, v. 3, n. 2, p. 107-120, 1998.

ALMEIDA, G. C. E. A Matemática nas Ciências Aplicadas: uma proposta metodológica. 1993. 121 p. Dissertação (Mestrado em Educação Matemática) - Universidade Santa Úrsula, Rio de Janeiro, 1993.

ARTIÈRES, P. Dizer a Atualidade: O trabalho de diagnóstico em Michel Foucault. In: GROS, F. (Org.). Foucault: a coragem da verdade. São Paulo: Parábola Editorial, 2004. p. 15-37.

BACHELARD, G. Conhecimento comum e conhecimento científico. Revista Tempo Brasileiro, Rio de Janeiro, n. 28, p. 27-46, jan./mar. 1972.

BIEMBENGUT, M. S. Modelação matemática como método de ensino-aprendizagem de matemática em cursos de 1. e 2. graus. 1990. 210 p. Dissertação (Mestrado em Educação Matemática) - Instituto de Geociências e Ciências Exatas, Universidade Estadual Paulista, Rio Claro, 1990. 
BIEMBENGUT, M. S. Qualidade no ensino de matemática na engenharia: uma proposta curricular e metodológica. 1997. 196 p. Tese (Doutorado em Engenharia de Produção) Departamento de Engenharia de Produção e Sistemas, Universidade Federal de Santa Catarina, Florianópolis, 1997.

BURAK, D. Modelagem Matemática: uma metodologia alternativa para o ensino de matemática na $5^{a}$ série. 1987. 186 p. Dissertação (Mestrado em Educação Matemática) - Programa de Pós-Graduação em Educação Matemática, Universidade Estadual Paulista Júlio Mesquita Filho, Rio Claro, 1987.

BURAK, D. Modelagem Matemática: ações e interações no processo de ensino-aprendizagem. 1992. 459 p. Tese (Doutorado em Educação) - Programa de Pós-Graduação em Educação, Faculdade de Educação da Universidade Estadual de Campinas, Campinas, 1992.

BURKE, P. A Revolução Francesa da historiografia: a Escola dos Annales 1929-1989. Tradução: Nilo Odália. São Paulo: Editora Universidade Estadual Paulista, 1991.

CALDEIRA, A. D. Educação Matemática e Ambiental: um contexto de mudança. 1998. 158 p. Tese (Doutorado em Educação) - Programa de Pós-Graduação em Educação, Universidade de Campinas, Campinas, 1998.

CUSTÓDIO, J. F. et al. Práticas didáticas construtivistas: critérios de análise e caracterização. Tecné, Episteme y Didaxis (TED), Bogotá, v. 33, n. 33, p. 11-35, jan./jun. 2013.

DELEUZE, G. Conversações. Rio de Janeiro: Editora 34, 2000.

DUARTE, C. G. Produzindo fissuras nas "verdades" da matemática. In: HENNING, P. C.; RIBEIRO, P. R. C.; SCHIMIDT, E. B. (Org.). Perspectivas de investigação em Educação Ambiental e Educação em Ciências. Rio Grande: FURG, 2011.

FIORENTINI, D. Estudo de algumas tentativas pioneiras de pesquisa sobre o uso da modelagem matemática no ensino. In: ICME, 8., 1996, Sevilha. Anais... Sevilha: ICME, 1996. p. 235-248.

FIORENTINI, D. Alguns modos de ver e conceber o ensino de matemática no Brasil. Zététiké, Campinas, ano 3, n. 4, p. 1-37, nov. 1995.

FLORIANI, I. A. A Educação Matemática no Processo de Formação do Professor das Séries Iniciais. 1997. 175 p. Dissertação (Mestrado em Educação) - Programa de Pós-Graduação em Educação, Universidade Regional de Blumenau, Blumenau, 1997.

FOSSILE, D. K. Construtivismo versus sócio-interacionismo: uma introdução às teorias cognitivas. Revista ALPHA, Patos de Minas, v. 1, n. 11, p. 105-117, ago. 2010.

FOUCAULT, M. Microfísica do poder. Rio de Janeiro: Graal, 2011.

FOUCAULT, M. A Arqueologia do Saber. Tradução de Luiz Felipe Baeta Neves. 8. ed. Rio de Janeiro: Forense Universitária, 2014.

FOUCAULT, M. Arqueologia das ciências e história dos sistemas de pensamento. Ditos e Escritos II. Organização e seleção de textos Manoel Barros da Motta. Tradução de Elisa Monteiro. 3. ed. Rio de Janeiro: Forense Universitária, 2013a.

FOUCAULT, M. Arqueologia das ciências e história dos sistemas de pensamento. Ditos e Escritos II. Organização e seleção de textos Manoel Barros da Motta. Tradução: Elisa Monteiro. 3. ed. Rio de Janeiro: Forense Universitária, 2013b. 
FOUCAULT. M. A ordem do discurso: aula inaugural no Collège de France, pronunciada em 2 de dezembro de 1970. Tradução de Laura Fraga de Almeida Sampaio. 24. ed. São Paulo: Edições Loyola, $2014 b$.

GAZZETTA, M. A Modelagem como Estratégia de Aprendizagem da Matemática em Cursos de Aperfeiçoamento de Professores. 1989. 150 p. Dissertação (Mestrado em Educação Matemática) Programa de Pós-Graduação em Educação Matemática, Universidade Estadual Paulista, Rio Claro, 1989.

KRASILCHIK, M. Reformas e realidade: o caso do ensino de ciências. São Paulo em Perspectiva, São Paulo, v. 14, n. 1, jan./mar. 2000.

LEÃO, D. M. M. Paradigmas contemporâneos de educação: escola tradicional e escola construtivista. Cadernos de Pesquisa, São Paulos, v. 29, n. 107, p. 187-206, jul. 1999.

LE GOFF, J. Foucault e a “nova história”. Plural, São Paulo, v. 10, n. 10, p. 197-209, 2003.

MACHADO, R. Foucault, a ciência e o saber. 3. ed. Rio de Janeiro: Jorge Zahar, 2007.

MAGNUS, M. C. M. Modelagem Matemática na Educação Matemática Brasileira: histórias em movimento. 2018. 227 p. Tese (Doutorado em Educação) - Programa de Pós-Graduação em Educação, Universidade Federal de São Carlos, São Carlos, 2018.

MATTHEWS, M. Construtivismo e o ensino de ciências: uma avaliação. Caderno Brasileiro de Ensino de Física, Florianópolis, v. 17, n. 3, p. 270-294, 2000.

MONTEIRO, A. O ensino de matemática para adultos através do método modelagem matemática. 1991.310 p. Dissertação (Mestrado em Educação Matemática) - Programa de PósGraduação em Educação Matemática, Universidade Estadual Paulista, Rio Claro, 1991.

MÜLLER, M. C. Modelos matemáticos no ensino da matemática. 1986. 140 f.

Dissertação (Mestrado em Educação) - Faculdade de Educação, Universidade Estadual de Campinas, Campinas, 1986.

NIEMANN, F. de; A. BRANDOLI, F. M. Jean Piaget: um aporte teórico para o construtivismo e suas contribuições para o processo de ensino e aprendizagem da Língua Portuguesa e da Matemática. In: SEMINÁRIO DE PESQUISA EM EDUCAÇÃO NA REGIÃO SUL - ANPED, 9., 2012, Caxias do Sul. Anais.... Caxias do Sul: ANPED, 2012. p. 1-14.

PEREIRA, L. de A. Entre clio e sophia: um mapeamento das relações entre história e filosofia através dos diálogos entre Michel Foucault e os historiadores dos Annales. 2013. $203 \mathrm{f}$. Tese (Doutorado em História) - Faculdade de Ciências e Letras, Universidade Estadual Paulista, Assis, 2013.

PORTOCARRERO, V. As ciências da vida: de Canguilhem a Foucault. Rio de Janeiro: Fiocruz, 2009.

REVAH, D. A (re)configuração do passado no discurso construtivista. Estilos da Clínica, São Paulo, v. 13, n. 24, p. 190-209, 2008.

SANCHIS, I. de P.; MAHFOUD, M. Construtivismo: desdobramentos teóricos e no campo da educação. Revista Eletrônica de Educação, São Carlos, v. 4, n. 1, p. 18-33, mai. 2010.

SÁNCHEZ, J. E. P. Estratégia combinada de módulos instrucionais e modelos matemáticos interdisciplinares para ensino-aprendizagem de matemática a nível de segundo grau: um estudo 
exploratório. 1979. 305 f. Dissertação (Mestrado em Educação) - Pontifícia Universidade Católica do Rio de Janeiro, Rio de Janeiro, 1979.

SCHEFFER. N. F. O encontro da educação matemática com a pedagogia Freinet. 1995. 275 p. Dissertação (Mestrado em Educação Matemática) - Instituto de Geociências e Ciências Exatas, Universidade Estadual Paulista, Rio Claro, 1995.

SILVA, M. P. O processo de apropriação de concepções construtivistas em materiais didáticos para alfabetização. Estudos Linguísticos, São Paulo, v. 40, n. 2, p. 509-523, mai./ago. 2011.

SILVEIRA, E. Modelagem matemática em educação no Brasil: entendendo o universo de teses e Dissertações. 2007. 204 f. Dissertação (Mestrado em Educação) - Universidade Federal do Paraná, Curitiba, 2007.

SKALINSKI JUNIOR, O. A difusão do construtivismo no Brasil a partir da década de 1980. ENCONTRO DE PESQUISA EM EDUCAÇÃO DA REGIÃO SUL - ANPED, 7., 2010, Londrina. Anais... Londrina: ANPED, 2010.

VASCONCELOS, M. S. A difusão das ideias de Piaget no Brasil. São Paulo: Casa do Psicólogo Livraria e Editora Ltda., 1996.

VEIGA-NETO, A. Foucault e a Educação. 2. ed. 1 reimp. Belo Horizonte: Autêntica, 2007.

WILMER, C. B. Modelos na aprendizagem da matemática. 1976. 150 f. Dissertação (Mestrado em Ciências da Matemática) - Pontifícia Universidade Católica do Rio de Janeiro, Rio de Janeiro, 1976.

Submetido em 29 de Janeiro de 2019. Aprovado em 18 de Julho de 2019. 